\title{
Energy contribution of NOVA food groups and socio-demographic determinants of ultra-processed groups among adults in Terengganu, Malaysia
}

\author{
*Asma', A., Wan Syakirah Alia, W.M.S., Aziz, Y. and Hayati, M.Y. \\ School of Food Science and Technology, Universiti Malaysia Terengganu (UMT), Terengganu, Malaysia
}

\author{
Article history: \\ Received: 6 April 2019 \\ Received in revised form: 5 \\ May 2019 \\ Accepted: 10 May 2019 \\ Available Online: 15 May \\ 2019
}

\section{Keywords:}

Ultra-processed food,

NOVA classification,

Socio-demographic,

Terengganu,

Malaysia

\section{DOI:}

https://doi.org/10.26656/fr.2017.3(6).150

\begin{abstract}
The Malaysian Nutrition Research Priorities for Malaysia's $11^{\text {th }}$ Plan noted the necessity to investigate in depth the consumption of ultra-processed food among the Malaysian population. No empirical research has focused on exploring the energy contribution of ultra-processed foods and the socio-demographic determinants of ultra-processed foods. Thus, this study was conducted to investigate the relationship between the increasing consumption of ultra-processed foods with socio-demographic factors particularly in Terengganu, Malaysia. This cross-sectional study provides a novel approach to quantifying energy contribution of 200 adults (living in Terengganu; aged 18 to 59 years) based on the ultra-processed food classification named as NOVA, via semi-quantitative Food Frequency Questionnaire, and to determine the association between energy contribution of ultra-processed foods and socio-demographic characteristics. The selfadministered questionnaire consists of three sections: socio-demographic profile, frequency of ultra-processed food consumption and energy contribution of NOVA food groups. All data were analysed using SPSS version 21. The findings show that the contribution of ultra-processed foods among respondents was lower (40.38\%) compared to unprocessed and minimally processed foods $(55.73 \%)$. The most frequent consumed ultraprocessed foods were noodles and fried chicken (fast food). Meanwhile, the least frequently consumed foods included frozen chicken pie and garlic spread. There were significant associations between the energy contribution of ultra-processed foods and marital status, educational level, monthly household income and occupational status meanwhile there was no significant association between age and gender at $p<0.05$. This study provides the first comprehensive assessment of ultra-processed foods consumption using NOVA classification via semi-quantitative FFQ in Malaysia.
\end{abstract}

\section{Introduction}

NOVA has received recognition from the Food and Agriculture Organization of the United Nations and the Pan American Health Organization as a valid tool for nutrition and public health research, policy and action (Monteiro et al., 2016). NOVA (a name, not an acronym) is a food classification that has been recently proposed as a new approach to classify all foods and beverages into four distinct groups according to the nature, extent and purpose of their processing, including unprocessed or minimally processed foods, processed culinary ingredients, and processed and ultra-processed foods, in order to study the role of industrial food processing in the nutritional transition (Monteiro et al., 2010). The rapid transition of eating habits from consuming freshly prepared meals from nutritious foods to ready to consume ultra-processed products that are nutritionally imbalanced clearly shows a remarkable increase in the consumption of ultra-processed products (Filippa and Erik, 2015). As estimated from the direct consumption of ultra-processed products, daily per capita energy intake in Sweden increased by $15 \%$, from 2820 kcal in 1960 to $3250 \mathrm{kcal}$ in 2010 (Filippa and Erik, 2015). In Canada, an average of $61.7 \%$ of daily energy was found to be contributed by ready-to-eat products; a total of $54.9 \%$ of energy came from the ultra-processed products (Moubarac et al., 2013). Meanwhile, in Mexico, $54.0 \%$ of the energy intake was contributed by unprocessed or minimally processed foods, and $29.8 \%$ of the energy contribution came from the ultra-processed products (Joaquín et al., 2018).

The consumption of ultra-processed food has been growing both in relative and absolute terms in high and middle-income countries, despite being higher in high- 
income countries (Moubarac et al., 2013). From 2002 until 2009, purchases of ultra-processed foods increased more among lower-income families than among higherincome families (Martins et al., 2013). The decreasing price of ultra-processed food could be the main factor for increasing consumption among the poorer classes. The purchase of ultra-processed food, which previously used to be higher among upper-income classes during the last two periods, has increased in all income groups mainly among those of lower income (Martins et al., 2013). Increased consumption of food such as fried foods, sugar and fat has been associated with those with low economic position meanwhile increased consumption of whole grains, lean meats, fish, low-fat dairy products and fresh fruits and vegetables has been associated with those with high socioeconomic position of those in the developed countries (Galobardes, 2001). In contrast to developing countries, aside from higher income people, individuals living in urban areas who are younger also tend to have a higher consumption of ultra-processed foods (Gustavo et al., 2017). Furthermore, women have the highest proportion of ultra-processed food intake compared to men, although the contribution of ultraprocessed foods to the overall diet was very similar between men and women (Thibault et al., 2018). Women living without a partner, with higher education, stable income and normal BMI consume ultra-processed foods more frequently (Marrón-Ponce et al., 2018). People with educational background advantages tend to purchase more fresh fruit and vegetables more regularly than the least educated (Garvin Turrell et al., 2002). In Mexico, $41.6 \%$ of participants that had consumed ultraprocessed products lived in households in which the head of the family had lower educational background status (Joaquín et al., 2018). Head of family's educational level was closely related to unprocessed or minimally processed food consumption since it related to the availability of healthier foods at home (Fernanda et al., 2016). All in all, socio-demographic may influence the energy contribution of each of the NOVA food groups.

Furthermore, studying consumption of ultraprocessed foods is crucial, as emphasized in the Nutrition Research Priorities for $11^{\text {th }}$ Malaysia Plan (2016-2025). There is strong evidence that increasing rates of obesity are due to the consumption of highenergy foods, such as processed foods which are higher in fats and sugars compared to the low-energy foods. According to the National Health and Morbidity Survey (NHMS), the rate of obesity in Terengganu has increased from $14.0 \%$ in 2011 to $18.6 \%$ in 2015 . A study by Malaysian Adult National Survey (MANS) showed that socio-economic developments such as urbanization and economic growth in the country are attributed largely towards the changes in the lifestyle and dietary habits of
Malaysians population over the last decade (Norimah et al., 2008). These developments have been important drivers for changes in lifestyle, such as less frequent meals at home and increased snacking (Filippa and Erik, 2015). Traditional dietary patterns based on unprocessed or minimally processed foods have been replaced with the rapidly growing products, and there has been no verification of the consistency of the associations between socioeconomic position and consumption of ultra-processed foods (Simões et al., 2018).

The association of ultra-processed food with different socio-demographic position indicators needs to be explored in order to verify the consistency of the associations between socio-demographic position and consumption of ultra-processed foods. This study is important in order to determine whether there is a relationship between the increasing consumption of ultra -processed foods and socio-demographic factors. Furthermore, Malaysia lacks national-level data of the consumption of ultra-processed foods and its relation to social and economic status. Research is much needed on various aspects, including the classification of the foods and several factors affecting the increasing consumption among the Malaysian population, especially in Terengganu.

\section{Materials and methods}

\subsection{Sampling plan}

This study was conducted in Kuala Nerus, a district in Terengganu. Kuala Nerus was purposely selected for its fast development, higher education institutes, as well as various industrial and housing areas. This study used convenience sampling in which adults with from 18 years old and above in Kuala Nerus was selected as the respondents. The minimum sample size derived from Cochran formula for this study was 162 respondents $\left(Z_{1}\right.$. $\alpha / 2=1.96$, prevalence proportion of obese in Terengganu $($ NHMS, 2015$)=28.9 \%$, and absolute error or precision $=0.07)$. The study was carried out between June and August 2018. A subject information sheet and informed consent were given to respondents prior to the data collection. Ethical approval for this study was attained from the Human Ethics Board of Committees of Universiti Malaysia Terengganu with reference number: UMT/JKEPM/2017/3.

\subsection{Food frequency questionnaire}

A total of 165 food items in the Food Frequency Questionnaire (FFQ) are listed in the Malaysian Adult Nutrition Survey (MANS). Food items consumed in the FFQ for the last month were assigned to four groups according to the NOVA food classification, which is based on the nature, extent, and purpose of industrial 
food processing: unprocessed or minimally processed foods and processed culinary ingredients; processed foods; and ultra-processed foods. Each food item listed was given a standard serving size based on the food album, Album Saiz Sajian Malaysia. The response format of the FFQ was per day, per week, and per month. Frequency of intake of the items in FFQ was estimated using the formula from Norimah et al. (2008). The conversion factor used to estimate food intake was based on the frequency of intake of each food.

\subsection{Energy contribution of NOVA food groups}

The energy contribution of the foods in the FFQ was estimated using the formula by the Wessex Institute of Public Health, 1995 and Norimah et al. (2008) as the following:

Energy value estimate $=$ Conversion factor $\mathrm{x}$ Serving size $\mathrm{x}$ Total number of serving $\mathrm{x}$ Weight of food in one serving

This equation contains the number of servings consumed per occasion times weight/serving size times daily intake frequency times nutritional composition of the food serving. The nutritional composition of each food serving was determined based on the Malaysian Food Composition table. The conversion factors are as shown in Table 1. The mean energy contribution for each NOVA food groups was calculated from the energy contribution obtained.

Table 1. Example of FFQ score

\begin{tabular}{lcc}
\hline Frequency of intake & Frequency & Conversion factor \\
\hline \multirow{3}{*}{ Per day } & Once & 1 \\
& Twice & 2 \\
& 3 times & 3 \\
Per week & Once & $1 / 7$ \\
& Twice & $2 / 7$ \\
& 3 times & $3 / 7$ \\
\multirow{4}{*}{ Per months } & 4 times & $4 / 7$ \\
& Once & $1 / 30$ \\
& Twice & $2 / 30$ \\
& 3 times & $3 / 30$ \\
\hline
\end{tabular}

Serving size of each food listed in the food frequency questionnaire was determined by using the formula shown below:

$$
\text { Serving size }=\frac{\text { Amount of food consume per day }}{\text { weight of serving size }}
$$

Based on the summation of NOVA groups, total energy contribution was obtained. The average energy contribution of each NOVA groups can be achieved to make comparisons concerning which groups contribute more energy in daily consumption.

Average energy contribution $(\%)=\frac{\text { Total energy contribution of a group in NOVA }}{\text { Total energy in a day }} \times 100$
2.4 Procedures to classify foods according to NOVA classification

The frequency of consumption of ultra-processed foods was evaluated according to the different classification based on the degree of processing underlying each group. Group 1 is unprocessed or minimally processed foods such as fresh, dry or frozen fruits and vegetables, packaged grains and pulses, flakes or flours made from corn and water. Group 2 is processed culinary ingredients that include sugar, oils, fats, salt and other ingredients used in the kitchens for seasoning or cooking the unprocessed or minimally processed foods. Group 3 includes processed food, which is similar to ready-to-eat products manufactured with the addition of unprocessed or minimally processed foods and salt, sugar and other substances of culinary use. Group 4 includes ultra-processed foods such as sweet, fatty or salty packaged snack products, ice-cream, chocolates, candies, mass-produced packaged bread, cookies, pastries, cakes and many ready-to-heat products. However, instead of having four stand-alone NOVA food groups, this study combined Group 1 and Group 2, leaving three main NOVA food groups; Group 1 and 2, Group 3 and Group 4.

All the listed food items were sorted according to each respective NOVA food groups in Microsoft Excel. From the FFQ data collection, the information needed to calculate the energy contribution was obtained. The calculation of energy calculation was done using Microsoft Excel. The energy contributions were needed in order to obtain the average for each group and compare the data between groups. The average for each group was calculated by dividing the energy contribution of each group with the total energy contribution for all groups.

\subsection{Data analysis}

All analyses were performed with the statistical software package IBM SPSS Statistics version 22. Estimated mean energy contributions of the three NOVA food groups were calculated in the Microsoft Excel. $\mathrm{p}<0.05$ is considered significant. Kolmogorov-Smirnov test was used in order to test the normality of data since it is suitable for the samples higher than 50. To determine the association between energy contribution and socio-demographic characteristics, the data were analysed using cross tabulation and Chi-Square. For normal distributed data, mean (SD) was used; meanwhile, for non-normal data, using the interquartile range (IQR), the mean values of the energy contributions for each food group were calculated. To find the differences between the average consumption in each group, the Kruskal-Wallis test was used. 


\section{Results}

\subsection{Socio-demographic characteristics of respondents}

Table 2. Socio-demographic profiles of the respondents $(n=200)$

\begin{tabular}{|c|c|c|}
\hline Socio-demographic profile & Frequency & Percentage $(\%)$ \\
\hline \multicolumn{3}{|l|}{ Age } \\
\hline $18-25$ & 61 & 30.5 \\
\hline $26-30$ & 34 & 17 \\
\hline $31-35$ & 54 & 27 \\
\hline $36-40$ & 24 & 12 \\
\hline $41-45$ & 9 & 4.5 \\
\hline $46-50$ & 6 & 3 \\
\hline $51-55$ & 9 & 4.4 \\
\hline $56-60$ & 3 & 1.5 \\
\hline \multicolumn{3}{|l|}{ Gender } \\
\hline Male & 50 & 25 \\
\hline Female & 150 & 75 \\
\hline \multicolumn{3}{|l|}{ Race } \\
\hline Malay & 184 & 92 \\
\hline Chinese & 14 & 7 \\
\hline Indian & 1 & 0.5 \\
\hline Others & 1 & 0.5 \\
\hline \multicolumn{3}{|l|}{ Religion } \\
\hline Muslim & 185 & 92.5 \\
\hline Buddha & 12 & 6 \\
\hline Hindu & 1 & 0.5 \\
\hline Others & 2 & 1 \\
\hline \multicolumn{3}{|l|}{ Marital status } \\
\hline Single & 79 & 39.5 \\
\hline Married & 114 & 57 \\
\hline Divorce & 6 & 3 \\
\hline Widow & 1 & 0.5 \\
\hline
\end{tabular}

\begin{tabular}{|c|c|c|}
\hline \multicolumn{3}{|l|}{ Educational status } \\
\hline Never attended school & 0 & 0 \\
\hline Primary school & 0 & 0 \\
\hline Secondary school & 43 & 21.5 \\
\hline Diploma & 48 & 24 \\
\hline Bachelor's degree & 86 & 43 \\
\hline Others & 23 & 11.5 \\
\hline \multicolumn{3}{|c|}{ Monthly household income } \\
\hline Less than RM3000 & 99 & 49.5 \\
\hline RM3000 - RM3999 & 44 & 22 \\
\hline RM4000 - RM4999 & 26 & 13 \\
\hline RM5000 - RM5999 & 14 & 7 \\
\hline RM6000 and above & 17 & 8.5 \\
\hline \multicolumn{3}{|l|}{ Occupational status } \\
\hline Clerk & 36 & 18 \\
\hline Student & 59 & 29.5 \\
\hline Businessman/woman & 7 & 3.5 \\
\hline Science Officer & 9 & 4.5 \\
\hline Security Guard & 8 & 4 \\
\hline Lecturer & 3 & 1.5 \\
\hline Staff & 47 & 23.5 \\
\hline Technician & 3 & 1.5 \\
\hline Others & 28 & 14 \\
\hline \multicolumn{3}{|l|}{ Daily cooking frequency } \\
\hline Yes & 78 & 39 \\
\hline No & 122 & 61 \\
\hline
\end{tabular}

Table 2 shows the socio-demographic characteristics of the respondents. This study involved 200 respondents from 18 to 59 years old in Kuala Nerus, Terengganu. Almost $87 \%$ of the respondents were aged from 18 to 40 years old. Most of the respondents were female, married, Malay, and Muslim. Most of them had a high educational level since $43 \%$ of respondents had a bachelor's degree. Approximately 49.5\% reported a monthly income of less than RM3000, considering that about one-third of the respondents were 18 to 25 years old. Most respondents were working, while $29.5 \%$ were students. This may be why $61 \%$ reported not cooking daily.

\subsection{Energy contribution of NOVA food groups via food frequency questionnaire ( $F F Q)$}

The energy from each NOVA food groups was determined using the FFQ together with the frequency and amount of serving size that they consumed. It can be seen from Table 3 that the highest percentage of 55.73\% came from Group 1 and 2, which are unprocessed and minimally processed food and processed culinary ingredients. $40.38 \%$ came from ultra-processed foods and other $3.89 \%$ came from processed foods.

Table 3 shows that the mean energy intake of adults in Kuala Nerus was $2238.00 \mathrm{kcal} \pm 1236$ where the average energy intake from Group 1 and 2, Group 3 and Group 4 were $1247.38 \mathrm{kcal}, 87.11 \mathrm{kcal}$ and $904.74 \mathrm{kcal}$, respectively. According to the Recommended Nutrient Intake (2005), the energy requirements for male adults age 19-59 years old who are moderately active range between $2190 \mathrm{kcal}$ and $2240 \mathrm{kcal}$. For female adults, energy requirements range between $1840 \mathrm{kcal}$ and 1900 $\mathrm{kcal}$. The results of total mean energy intake are higher for females according to the recommendation of RNI. Conversely, it was still within the acceptable range for males.

\subsection{Frequency of consumption of ultra-processed foods among adults in Kuala Nerus}

From Table 4, it can be seen that the most consumed ultra-processed foods by adults in Kuala Nerus included noodles, frozen fried chicken, cream crackers, oyster sauce, white bread, commercial milk and keropok lekor. Of 200 respondents, only 20 respondents $(10.0 \%)$ did not eat noodles at all for the whole month. Additionally, only 29 respondents (14.5\%) did not consume fried chicken in a month. Only 31 respondents $(15.5 \%)$ did not eat white bread for the whole month and 10 respondents $(5.0 \%)$ ate white bread every day. However, 74 respondents (37.0\%) did not consume commercial milk at all in a month and 6 respondents $(3.0 \%)$ consumed it every day. Interestingly, 43 respondents $(21.5 \%)$ ate keropok lekor 
Table 3. Mean energy contribution of Group 1+2, Group 3 and Group 4 and their percentage

\begin{tabular}{ccc}
\hline Total energy intake by NOVA food & Percentage of contribution from each group & Mean \pm SD \\
\hline Total energy intake (kcal) & & $2238.00 \pm 1236$ \\
\hline Total energy intake for : & 55.73 & $1247.38 \pm 684$ \\
\hline Group 1 + 2 (kcal) & 3.89 & $87.11 \pm 130$ \\
Group 3 (kcal) & 40.38 & $903.74 \pm 716$ \\
\hline Group 4 (kcal) & & \\
\hline
\end{tabular}

Table 4. Most- and least- frequent ultra-processed foods consumed by adults in Kuala Nerus

\begin{tabular}{lccccc}
\hline \multicolumn{5}{c}{ Ultra-processed foods consumption in a month } & \\
\hline \multirow{2}{*}{ Frequency } & Not consumed & $1-2$ times & $3-4$ times & $5-6$ times & Every day \\
\cline { 2 - 6 } & $\mathrm{n}(\%)$ & $\mathrm{n}(\%)$ & $\mathrm{n}(\%)$ & $\mathrm{n}(\%)$ & $\mathrm{n}(\%)$ \\
\hline Most frequent ultra-processed foods & $20(10.0)$ & $36(18.0)$ & $36(18.0)$ & $64(32.0)$ & $44(22.0)$ \\
\hline Noodle & $29(14.5)$ & $44(22.0)$ & $31(15.5)$ & $58(29.0)$ & $38(19.0)$ \\
Fried chicken (fast food) & $84(42.0)$ & $31(15.5)$ & $24(12.0)$ & $33(16.5)$ & $28(14.0)$ \\
Cream crackers & $73(36.5)$ & $9(4.5)$ & $24(12.0)$ & $72(36.0)$ & $22(11.0)$ \\
Oyster sauce & $31(15.5)$ & $58(29.0)$ & $54(27.0)$ & $47(23.5)$ & $10(5.0)$ \\
White bread & $74(37.0)$ & $35(17.5)$ & $32(16.0)$ & $53(26.5)$ & $6(3.0)$ \\
Commercial milk & $66(33.0)$ & $52(26.0)$ & $36(18.0)$ & $43(21.5)$ & $3(1.5)$ \\
Keropok lekor & $184(92.0)$ & $8(4.0)$ & & & $2(1.0)$ \\
\hline Least frequent ultra-processed foods & $13(6.5)$ & $2(1.0)$ & $2(1.0)$ & $0(0.0)$ \\
Frozen chicken pie & $183(91.5)$ & $10(5.0)$ & $1(0.5)$ & $5(2.5)$ & $0(0.0)$ \\
Garlic spread & $183(91.5)$ & $8(4.0)$ & $8(4.0)$ & $4(2.0)$ & $1(0.5)$ \\
Frozen mixed vegetables & $179(89.5)$ & $10(5.0)$ & $5(2.5)$ & $10(5.0)$ & $1(0.5)$ \\
Frozen sweet corn & $174(87.0)$ & $19(9.5)$ & $1(0.5)$ & $7(3.5)$ & $1(0.5)$ \\
Frozen meatballs & $173(86.5)$ & $12(6.0)$ & $10(5.0)$ & $5(2.5)$ & $0(0.0)$ \\
Frozen potato wedges & $173(86.5)$ & $15(7.5)$ & $6(3.0)$ & $11(5.5)$ & $0(0.0)$ \\
Hash brown & $168(84.0)$ & & $0(0.0)$ \\
Cream cheese & & &
\end{tabular}

Table 5. Association between ultra-processed foods and socio-demographic characteristics

\begin{tabular}{|c|c|c|c|c|c|c|}
\hline \multirow{3}{*}{$\begin{array}{l}\text { Socio-demographic } \\
\text { characteristics }\end{array}$} & \multirow{3}{*}{ Classification } & \multicolumn{4}{|c|}{ Ultra-processed foods consumption } & \multirow{3}{*}{ p-value } \\
\hline & & \multicolumn{2}{|c|}{$<30 \%$ energy intake } & \multicolumn{2}{|c|}{$>30 \%$ energy intake } & \\
\hline & & $\mathrm{N}$ & $\%$ & $\mathrm{n}$ & $\%$ & \\
\hline \multirow{2}{*}{ Age } & Below 40 & 76 & 43.7 & 98 & 56.3 & $\left(X^{2}=4.284\right)$ \\
\hline & 40 and above & 17 & 65.4 & 9 & 34.6 & 0.056 \\
\hline \multirow{2}{*}{ Gender } & Male & 19 & 38 & 31 & 62 & $\left(X^{2}=1.936\right)$ \\
\hline & Female & 74 & 49.3 & 76 & 50.7 & 0.192 \\
\hline \multirow{2}{*}{ Race } & Malay & 89 & 48.4 & 95 & 51.6 & $\left(\mathrm{X}^{2}=3.231\right)$ \\
\hline & Others & 4 & 25 & 12 & 75 & 0.115 \\
\hline \multirow{2}{*}{ Religion } & Muslim & 89 & 48.1 & 96 & 51.9 & $\left(X^{2}=2.564\right)$ \\
\hline & Others & 4 & 26.7 & 11 & 73.3 & 0.177 \\
\hline \multirow{2}{*}{ Marital status } & Married & 63 & 55.3 & 51 & 44.7 & $\left(X^{2}=8.184\right)$ \\
\hline & Not married & 30 & 34.9 & 56 & 65.1 & $0.006^{*}$ \\
\hline \multirow{2}{*}{ Educational background } & $\begin{array}{l}\text { Lower than bachelor's } \\
\text { degree }\end{array}$ & 53 & 57.6 & 39 & 42.4 & $\left(X^{2}=8.451\right)$ \\
\hline & $\begin{array}{l}\text { Bachelor's degree and } \\
\text { above }\end{array}$ & 40 & 37 & 68 & 63 & $0.004 *$ \\
\hline \multirow{2}{*}{ Monthly household income } & Lower than RM3000 & 39 & 37.9 & 64 & 62.1 & $\left(X^{2}=6.367\right)$ \\
\hline & RM3000 and above & 54 & 55.7 & 43 & 44.3 & $0.016^{*}$ \\
\hline \multirow{2}{*}{ Occupational status } & Working & 76 & 54.3 & 64 & 45.7 & $\left(X^{2}=11.371\right)$ \\
\hline & Unemployed & 17 & 28.3 & 43 & 71.7 & $0.001 *$ \\
\hline
\end{tabular}

*Significant at $\mathrm{p}<0.05$ 
5-6 times per month.

Table 4 illustrates the least frequent ultra-processed foods consumed by adults in Kuala Nerus. The least consumed ultra-processed foods were frozen chicken pie, garlic spread, frozen mixed vegetables, frozen sweet corn, frozen meatballs, frozen potato wedges, hash brown and cream cheese. From the results, a majority of the respondents $(92.0 \%)$ did not consume frozen chicken pie in a month. 183 respondents $(91.5 \%)$ also did not consume garlic spread at all in a month. Meanwhile, for hash browns and cream cheese, both had similar results, as no respondents consumed these every day.

\subsection{Association between energy contribution of ultra- processed foods and socio-demographic characteristics}

The association between energy contribution of ultra -processed foods and socio-demographic characteristics was analysed using Chi-square test since the data is not normal. Ultra-processed foods consumption was classified into less than $30 \%$ of energy intake and more than $30 \%$ energy intake in order to determine the level of consumption. According to Monteiro et al. (2010), an average daily energy intake $<30 \%$ is an indicator of low consumption of ultra-processed foods meanwhile $>30 \%$ indicates high consumption of ultra-processed foods.

Based on Table 5, marital status, educational background, monthly household income and occupational status had significant associations with ultra -processed foods consumption $(p<0.05)$, while age, gender, race and religion had no significant association $(p>0.05)$. Contrary to expectations, the findings slightly differ compared to previous studies. Studies have proven that age and gender had a significant association with the consumption of ultra-processed foods.

\section{Discussion}

4.1 Energy contribution of NOVA food groups via food frequency questionnaire ( $F F Q$ )

It was apparent that most of the energy intake in a month by the adult came from Group 1 and 2 (about $56 \%$ ), which include foods that are mostly unprocessed or involve minimal processing, such as meat, poultry, fresh, dry or frozen fruits and vegetables, packed grains and flours made from corn and water. Food in Group 2 are usually inedible by themselves, high in energy density and lower in nutrients compared to the whole foods that they were extracted from and are typically used in the preparation of the dishes making up Group 1 (Monteiro et al., 2010). The least energy contribution came from Group 3 (about 4\%), which includes food manufactured by adding culinary ingredients and includes process such as canning, bottling and fermentation (Fardet et al., 2015). Group 4, which contributes $904 \mathrm{kcal}$, includes ultra-processed foods including snack products, ice cream, chocolates, candies and many ready-to-heat products.

Ultra-processed foods were formulated to replace freshly prepared foods based on unprocessed and minimally processed groups (Fardet et al., 2015). The results show that the energy that came from ultraprocessed groups were slightly lower compared to the unprocessed and minimally processed group which can be assumed that the respondents preferred to prepare foods from scratch using raw materials instead of consuming processed foods. However, almost $41 \%$ of the consumption of ultra-processed and processed foods could be caused by time constraints. People tend to consume processed foods in order to save time and when there is no source of raw foods to be cooked.

In certain countries, particularly developed countries such as the United Kingdom, the consumption of ultraprocessed foods is higher compared to unprocessed or minimally processed foods because there has been a rapid development of ultra-processed foods with lower prices (Marrón-Ponce et al., 2018). While the development of ultra-processed foods is still lower in Kuala Nerus compared to unprocessed or minimally processed foods, average energy of $904 \mathrm{kcal}$ in a day is still considered high. A study by Setyowati et al. (2018), in Jakarta, found similar results, as energy consumption of ultra-processed foods among the Indonesian population was lower compared to unprocessed or minimally processed foods. Despite being less consumed, an increasing trend of ultra-processed foods consumption is apparent in both Malaysia and Indonesia. The characteristics of ultra-processed foods which are high in fat, salt and glycaemic loads will lead to increased cases of obesity and diet-related noncommunicable diseases (NCD) globally (Swinburn et al., 2007).

\subsection{Frequency of consumption of ultra-processed foods among adults in Kuala Nerus}

The most consumed ultra-processed foods by adults in Kuala Nerus were noodles, frozen fried chicken, cream crackers, oyster sauce, white bread, commercial milk and keropok lekor. The main fast food restaurants in Malaysia are very competitive in terms of pricing. They continuously lower their prices to make it affordable to all people (Mohamed and Daud, 2012). According to Habib et al. (2011), 84\% of Malaysian students consume fast food, thereby explaining the higher consumption at almost $41 \%$ of energy intake from ultra-processed foods, since most of the respondents in this study were students. 
Bread is surprisingly commonly consumed by adults in Kuala Nerus since it can be easily consumed especially during breakfast, during which working people do not have enough time. Among ultra-processed foods, bread contributes a higher amount of energy which is $9.2 \%$ of energy intakes compared to pizza, hamburgers, and cakes (Louzada et al., 2015). According to Norimah et al. (2008), bread and noodles have been listed as the top 10 weekly consumed foods by Malaysian with mean frequencies ranging from 1.79 to 2.73 .

Full cream milk was the second most daily consumed by Malay women, compared to men who preferred consuming sweetened condensed milk frequently (Norimah et al., 2008). This indicates that women are more aware of the health benefits of milk. According to Chee et al. (2003), milk drinking significantly lowers the risk of osteoporosis, thus explaining the high consumption among women. Keropok lekor is a traditional food in Terengganu. It is associated with localities and certain areas, thus explaining the high frequency of consumption in Kuala Nerus.

The least consumed ultra-processed foods were frozen chicken pie, garlic spread, frozen mixed vegetables, frozen sweet corn, frozen meatballs, frozen potato wedges, hash browns and cream cheese. The trend of eating away from home had become habitual to the young generation where they do not have to spend time on cooking due to time restrictions (Rahman et al., 2018). According to Marry et al. (2014), eating out is defined as consuming foods outside the house which require no cooking at all. Even though frozen foods are convenient and require less time cooking, especially frozen chicken pies that only need to be heated for a few minutes before being consumed, eating out is much easier.

\subsection{Association between energy contribution of ultra- processed foods and socio-demographic characteristics}

Marital status, educational level, monthly household income and occupational status showed strong evidence for an association related to the consumption of ultraprocessed foods. A high educational status involuntarily leads to having high occupational status and monthly household income. According to Cediel et al. (2018), the consumption of ultra-processed food tends to increase with the increasing monthly household income since the price of ultra-processed foods became affordable to the high monthly income groups. In high-income countries such as the United States, the production of ultraprocessed foods is highly concentrated, thus changing the food consumption patterns based on affordability
(Rayner et al., 2006). However, food consumption patterns in Asian middle-income countries including Malaysia, China and Thailand have already shown increasing consumption of ultra-processed foods, since the rapid development of ultra-processed foods and beverages manufacturing is on-going (Baker and Friel, 2016).

According to Adams and White, (2015), the consumption of ultra-processed foods shows significant correlation with age. The consumption of ultra-processed foods tends to decrease with age since older people tend to cook and eat healthy foods rather than consuming ultra-processed foods that are high in energy density and low in nutrient density. Gender had no significant association with the consumption of ultra-processed foods since several studies have shown differing results for gender and the association with ultra-processed foods. According to Djupegot et al. (2017), men more commonly consume ultra-processed foods compared to women; however, a study by Simões et al. (2018) shows the opposite finding, proving that gender has no association with the consumption of ultra-processed foods.

Even though the energy contribution that came from ultra-processed foods in Kuala Nerus is still less than unprocessed or minimally processed foods, the frequent consumption will relatively lead to the diet-related noncommunicable disease (NCD). This identification will be beneficial in order to promote healthy eating among groups that consume lower energy foods from the unprocessed or minimally processed groups. It is also important in order to keep track of the trend towards the consumption of ultra-processed foods that has developed rapidly in Malaysia. Dietary patterns have shifted from the intake of homemade meals towards ready-to-eat, packaged and convenience foods (Moubarac et al., 2017).

\section{Conclusion}

This study set out to classify foods according to NOVA food classification and explore the influence of socio-demographic factors towards ultra-processed food consumption. One of the more significant findings to emerge from this study is that ultra-processed foods, with a percentage contribution of around $40 \%$, were slightly less consumed compared by unprocessed or minimally processed foods, which contribute about 55\% of energy. The association of energy contribution from ultra-processed foods shows no significance with age and gender. However, the results show significant associations between socio-demographic characteristics including marital status, educational level, occupational 
status and monthly household income. Therefore, it can be concluded that it is important to determine the factors that influence the energy contribution from ultraprocessed foods in the prevention of higher consumption towards it in the future. This study provides the first comprehensive assessment of ultra-processed foods consumption using NOVA classification via semiquantitative FFQ in Malaysia. This NOVA approach will prove useful in expanding our understanding of ultraprocessed food consumption in Malaysia and specifically in Terengganu. This particular study will also help the Ministry of Health Malaysia gather data on the consumption of ultra-processed foods since this has been a major contributor to the non-communicable disease (NCD) development. Even though NCDs were not part of the 2000 Millennium Development Goals, in 2011 they became a focus, with the United Nations and the World Health Organization calling for a $25 \%$ reduction in NCD-related mortality by 2025 .

The study is limited by the lack of information on NOVA approach in Malaysia. A limitation of using this FFQ is that it only affords the capture of the listed items of ultra-processed foods in the questionnaire. Thus, the actual consumption of ultra-processed foods could not be meticulously studied. Furthermore, the listed items on the FFQ were slightly confusing for a few of the respondents since it involved too many foods. Finally, the generalisability of these findings is limited to adults in Kuala Nerus. Even though NOVA food classification was introduced to classify foods based on the extent and purpose of their processing, it could be better used in the future if the development of it is well-upgraded. In terms of directions for future research, further work could include more items especially from ultra-processed groups for the data to be more significant since nowadays various ultra-processed foods that are newly produced can be found in the market. Moreover, to make it clear for the respondents and avoid any errors during data collection, adding a description or picture to describe each food item could be used to improve future studies. Improvements can be made by conducting the study in larger areas and involving larger populations. Therefore, a number of possible future studies using the same NOVA approach are apparent.

\section{Conflict of interest}

The authors declare there is no conflict of interest.

\section{Acknowledgement}

This study is funded under the Universiti Malaysia Terengganu (UMT)'s Tabung Penyelidik Muda scheme (No. Vot: 68007/2016/83).

\section{References}

Adams, J. and White, M. (2015). Characterisation of UK diets according to degree of food processing and associations with socio-demographics and obesity: cross-sectional analysis of UK National Diet and Nutrition Survey (2008-2012). International Journal of Behavioural Nutrition and Physical Activity, 12 (1), 160. https://doi.org/10.1186/s12966-015-0317-y

Baker, P. and Friel, S. (2016). Food systems transformations, ultra-processed food markets and the nutrition transition in Asia. Globalization and Health, 12(1), 80. https://doi.org/10.1186/s12992016-0223-3

Cediel, G., Reyes, M., da Costa Louzada, M.L., Steele, E.M., Monteiro, C.A., Corvalán, C. and Uauy, R. (2018). Ultra-processed foods and added sugars in the Chilean diet (2010). Public Health Nutrition, 21 (1), 125-133. https://doi.org/10.1017/ S1368980017001161

Chee, W.S.S., Suriah, A.R., Chan, S.P., Zaitun, Y. and Chan, Y.M. (2003). The effect of milk supplementation on bone mineral density in postmenopausal Chinese women in Malaysia. Osteoporosis International, 14(10), 828-834. https:// doi.org/10.1007/s00198-003-1448-6

Djupegot, I.L., Nenseth, C.B., Bere, E., Bjørnarå, H.B.T., Helland, S.H., Øverby, N.C., Torstveit, M.K. and Stea, T.H. (2017). The association between time scarcity, sociodemographic correlates and consumption of ultra-processed foods among parents in Norway: a cross-sectional study. BMC Public Health, 17(1), 447. https://doi.org/10.1186/s12889017-4408-3

Fardet, A., Rock, E., Bassama, J., Bohuon, P., Prabhasankar, P., Monteiro, C., Moubarac, J.C. and Achir, N. (2015). Current food classifications in epidemiological studies do not enable solid nutritional recommendations for preventing dietrelated chronic diseases: the impact of food processing. Advances in Nutrition, 6(6), 629-638. https://doi.org/10.3945/an.115.008789

Filippa, J. and Erik, H. (2015). Trends in consumption of ultra-processed foods and obesity in Sweden between 1960 and 2010. Public Health Nutrition, 18 (17), 3096-3107. https://doi.org/10.1017/ S1368980015000506

Habib, F.Q., Abu Dardak, R. and Zakaria, S. (2011). Consumers' preference and consumption towards fast food: Evidences from Malaysia. Business and Management Quarterly Review, 2(1), 14-27.

Joaquín A., Marrón-Ponce, Sánchez-Pimienta, T.G., da Costa Louzada, M L. and Batis, C. (2018). Energy 
contribution of NOVA food groups and sociodemographic determinants of ultra-processed food consumption in the Mexican population. Public Health Nutrition, 21(1), 87-93. https:// doi.org/10.1017/S1368980017002129

Louzada, M.L., Baraldi, L.G., Steele, E.M., Martins, A.P.B., Canella, D.S., Moubarac, J.C., Levy, R.B., Cannon, G., Afshin, A., Imamura, F. and Mozaffarian, D. (2015). Consumption of ultraprocessed foods and obesity in Brazilian adolescents and adults. Preventive Medicine, 81, 9-15. https:// doi.org/10.1016/j.ypmed.2015.07.018

Marrón-Ponce, J.A., Sánchez-Pimienta, T.G., da Costa Louzada, M.L. and Batis, C. (2018). Energy contribution of NOVA food groups and sociodemographic determinants of ultra-processed food consumption in the Mexican population. Public Health Nutrition, 21(1), 87-93. https:// doi.org/10.1017/S1368980017002129

Marry, T.P., Langgat, J. and Marzuki, K.M. (2014). Study on Generation Y Dining Out Behavior in Sabah, Malaysia. International Journal of Business and Social Science, 5(11), 92-101

Mohamed, R.N. and Daud, N.M. (2012). Cultural uncertainty on brand trust of fast food industry in Malaysia. Procedia-Social and Behavioural Sciences, 42, 399-412. https://doi.org/10.1016/ j.sbspro.2012.04.204

Monteiro, C.A., Levy, R.B., Claro, R.M., Castro, I.R.R.D. and Cannon, G. (2010). A new classification of foods based on the extent and purpose of their processing. Cadernos de Saude Publica, 26(11), 2039-2049. https://doi.org/10.1590/ S0102-311X2010001100005

Monteiro, C.A., Cannon, G., Levy, R., Moubarac, J.C., Jaime, P., Martins, A.P., Canella, D., Louzada, M. and Parra, D. (2016). NOVA. The star shines bright. World Nutrition, 7(1-3), 28-38.

Moubarac, J.C., Martins, A.P.B., Claro, R.M., Levy, R.B., Cannon, G. and Monteiro, C.A. (2013). Consumption of ultra-processed foods and likely impact on human health. Evidence from Canada. Public Health Nutrition, 16(12), 2240-2248. https:// doi.org/10.1017/S1368980012005009

Moubarac, J.C., Batal, M., Louzada, M.L., Steele, E.M. and Monteiro, C.A. (2017). Consumption of ultraprocessed foods predicts diet quality in Canada. Appetite, 108, 512-520. https://doi.org/10.1016/ j.appet.2016.11.006

Norimah, A.K., Safiah, M., Jamal, K., Haslinda, S., Zuhaida, H., Rohida, S., Fatimah, S., Norazlin, S., Poh, B.K., Kandiah, M. and Zalilah, M.S. (2008).
Food consumption patterns: findings from the Malaysian Adult Nutrition Survey (MANS). Malaysian Journal of Nutrition, 14(1), 25- 39.

Rahman, S.A.G., Ab Karim, S., Ishak, F.A.C. and Arshad, M.M. (2018). Understanding the Young Generations'preference Towards Malay Traditional Food in Malaysia. Journal of Tourism, 3(9), 42-57.

Rayner, G., Hawkes, C., Lang, T. and Bello, W. (2006). Trade liberalization and the diet transition: a public health response. Health Promotion International, 21 (Suppl. 1), 67-74. https://doi.org/10.1093/heapro/ da1053

Recommended Nutrient Intake for Malaysia. (2005). Retrieved from website: http:// nsm.nutritionmonthmalaysia.org.my/recommendednutrient-intakes-for-malaysia-2005/

Setyowati, D., Andarwulan, N. and Giriwono, P.E. (2018). Processed and ultraprocessed food consumption pattern in the Jakarta Individual Food Consumption Survey 2014. Asia Pacific Journal of Clinical Nutrition, 27(4), 840.

Simões, B.D.S., Cardoso, L.D.O., Benseñor, I.J.M., Schmidt, M.I., Duncan, B.B., Luft, V.C., Molina, M.D.C.B., Barreto, S.M., Levy, R.B. and Giatti, L. (2018). Consumption of ultra-processed foods and socioeconomic position: a cross-sectional analysis of the Brazilian Longitudinal Study of Adult Health. Cadernos de Saude Publica, 34, e0019717. https:// doi.org/10.1590/0102-311x00019717

Swinburn, B.A., Sanigorski, A.M. and Bell, A.C. (2007). Association of key foods and beverages with obesity in Australian schoolchildren. Public Health Nutrition, 10(2), 152-157. https://doi.org/10.1017/ S1368980007246634 